\title{
Erratum to: Streptacidiphilus durhamensis sp. nov., isolated from a spruce forest soil
}

\author{
Patrycja Golinska • Lina Ahmed · Dylan Wang • \\ Michael Goodfellow
}

Published online: 3 September 2013

(C) Springer Science+Business Media Dordrecht 2013

\section{Erratum to: Antonie van Leeuwenhoek (2013) 104:199-206 \\ DOI 10.1007/s10482-013-9938-9}

In the original publication, the KACC number is given as 17155 in the species description section and
NCIMB number is mentioned as 14829 in the abstract and the description of the species section. However, the correct KACC number is 17154 and the NCIMB number is 14828 .
The online version of the original article can be found under doi:10.1007/s10482-013-9938-9.

P. Golinska · L. Ahmed · D. Wang · M. Goodfellow School of Biology, University of Newcastle, Newcastle upon Tyne NE1 7RU, UK

P. Golinska ( $\square)$

Department of Microbiology, Nicolaus Copernicus University, 87100 Torun, Poland

e-mail: golinska@umk.pl

D. Wang

Institute of Microbiology, Chinese Academy of Sciences, Beijing 100101, People's Republic of China 